\title{
Anti-tumor activities of peptides corresponding to conserved complementary determining regions from different immunoglobulins
}

\author{
Carlos R. Figueiredo ${ }^{a}$, Alisson L. Matsuo ${ }^{a}$, Mariana H. Massaoka ${ }^{a}$, Luciano Polonelli ${ }^{b}$, \\ Luiz R. Travassos ${ }^{\mathrm{a}, \mathrm{c}, *}$ \\ a Experimental Oncology Unit (UNONEX), Department of Microbiology, Immunology and Parasitology, Federal University of São Paulo, SP, Brazil \\ ${ }^{\mathrm{b}}$ Microbiology and Virology Unit, Department of Biomedical, Biotechnological and Translational Sciences, Universitá degli Studi di Parma, \\ Parma 43121, Italy \\ ${ }^{\mathrm{c}}$ Recepta Biopharma, São Paulo, SP, Brazil
}

\section{A R T I C L E I N F O}

\section{Article history:}

Received 23 May 2014

Received in revised form 11 June 2014

Accepted 12 June 2014

Available online 24 June 2014

\section{Keywords:}

Peptide

CDR

Cytotoxicity

Antitumor activity

Melanoma

\begin{abstract}
A B S T R A C T
Short synthetic peptides corresponding to sequences of complementarity-determining regions (CDRs) from different immunoglobulin families have been shown to induce antimicrobial, antiviral and antitumor activities regardless of the specificity of the original monoclonal antibody (mAb). Presently, we studied the in vitro and in vivo antitumor activity of synthetic peptides derived from conserved CDR sequences of different immunoglobulins against human tumor cell lines and murine B16F10-Nex2 melanoma aiming at the discovery of candidate molecules for cancer therapy. Four light- and heavy-chain CDR peptide sequences from different antibodies (C36-L1, HA9-H2, 1-H2 and Mg16-H2) showed cytotoxic activity against murine melanoma and a panel of human tumor cell lineages in vitro. Importantly, they also exerted anti-metastatic activity using a syngeneic melanoma model in mice. Other peptides (D07H3, MN20v1, MS2-H3) were also protective against metastatic melanoma, without showing significant cytotoxicity against tumor cells in vitro. In this case, we suggest that these peptides may act as immune adjuvants in vivo. As observed, peptides induced nitric oxide production in bone-marrow macrophages showing that innate immune cells can also be modulated by these CDR peptides. The present screening supports the search in immunoglobulins of rather frequent CDR sequences that are endowed with specific antitumor properties and may be candidates to be developed as anti-cancer drugs.
\end{abstract}

(c) 2014 Elsevier Inc. All rights reserved.

\section{Introduction}

Chemotherapy is a major approach to treat various cancers. Side effects, however, are commonly reported because of the inability to deliver the appropriate amount of drug specifically to tumor cells without affecting normal cells. Drug resistance, clearance and biodistribution are also problems to be faced in the various treatment protocols [7]. Aiming at specifically targeting tumor cells and endothelial cells of neoangiogenesis, or to stimulate the immune system, proteins, monoclonal antibodies and peptides have been used [26]. Due to size restrictions, antibodies and large protein ligands may have poor delivery to tumors and exhibit toxicity to the

\footnotetext{
* Corresponding author at: Experimental Oncology Unit (UNONEX), Department of Microbiology, Immunology and Parasitology, Federal University of São Paulo, SP, Brazil. Tel.: +55 115576 4551x1516; fax: +55 1155715877 .

E-mail addresses: luiztravassos@gmail.com, travassos@unifesp.br (L.R. Travassos).
}

liver and bone marrow. In contrast, peptides have the advantage of small size, good tumor penetration and biocompatibility.

Apart from the immune peptides derived from tumor cell protein antigens that are mostly known as $\mathrm{T} C D 8^{+}$epitopes, anticancer peptides can act directly through inhibition of angiogenesis, induction of apoptosis or by inhibiting protein-protein interactions, signal transduction pathways, enzymes and gene expression $[7,10,20,26,27]$. Some of them penetrate tumor cells and remodel actin cytoskeleton with inhibitory effects on cell migration [8] or severely affect actin dynamics leading tumor cells to apoptosis [2]

Short-sized peptides can act directly on tumor cells without affecting normal cells, thus evolving as an alternate strategy to conventional chemotherapy [26]. Peptides can also act as carriers of cytotoxic agents and radioisotopes conveying them to the tumor microenvironment. Those derived from native proteins have been described to present antimicrobial activities similar to peptides of innate immunity (defensins, cathelicidins, histatins) [6]. More than 30 peptides and their oncolytic properties against solid tumors have been recently reviewed [13]. 
In a previous work, Polonelli et al. [24] showed that synthetic CDR peptides can exhibit different antimicrobial, antiviral and antitumor activities in vitro, in vivo and/or ex vivo, in a way that was compared to early molecules of innate immunity [17]. This contribution extended previous results showing the remarkable therapeutic activity of an engineered synthetic peptide included in the variable region of a recombinant yeast killer toxin-like anti-idiotypic antibody against experimental mucosal and systemic candidiasis [23]. Both articles opened a new field of interest focusing on the bioactivity of internal sequences of immunoglobulins [18]. As a prototype of the CDR bioactive peptides, $\mathrm{C} 7 \mathrm{H} 2$ derived from mAb C7 $\mathrm{V}_{\mathrm{H}}$ CDR 2, showed significant antitumor activity in vitro and in vivo [24] notwithstanding the original specificity of the $\mathrm{mAb}$, directed to a Candida albicans cell wall mannoprotein. $\mathrm{C} 7 \mathrm{H} 2$ induces apoptosis in melanoma cells, by interacting with, and altering $\beta$-actin dynamics associated with abundant generation of superoxide anions [2]. Additional evidence of IgM/IgG-CDR-derived synthetic peptides with antitumor activities, including the description of microantibodies, has also been obtained [9]. The prototype, a 17-amino acid microantibody, derived from a mouse mAb was able to inactivate HIV in vitro [14].

Recent evidence on immunomodulatory activities of Ig-CDR peptides has also been obtained [11,19]. Cytotoxic effects have also been described for constant regions of immunoglobulins [12,22]. As a proof of concept of the bioactive potential of Ab CDR peptide sequences, we extended these studies and report on the differential antitumor activities of synthetic peptides with sequences identical to CDRs of the light $\left(\mathrm{L}_{1}\right.$ and $\left.\mathrm{L}_{3}\right)$ and heavy $\left(\mathrm{H}_{2}\right.$ and $\left.\mathrm{H}_{3}\right)$ chains of different immunoglobulin families. The CDRs chosen have more often been implicated in bioactivity than $\mathrm{L}_{2}$ and $\mathrm{H}_{1}$. We show here the biological activity of different CDR peptides as promising molecules displaying relevant in vitro and in vivo antitumor activities against malignant melanoma.

\section{Experimental}

\section{CDR peptide design and synthesis}

The CDR amino acid sequences were obtained according to the rules of Kabat [15] and Chothia [1,4] beyond the AbM method, or "definition of AbM" created from Accelrys software (Oxford Molecular's AbM or antibody modeling software), as described. The protein BLAST program of NCBI-NLM was used for choosing the CDR sequences with more than $80 \%$ homology within a family of immunoglobulins. Priority was given to CDRs derived from variable light chains $\mathrm{L}_{1}$ and $\mathrm{L}_{3}$ and heavy chains $\mathrm{H}_{2}$ and $\mathrm{H}_{3}$. Table 1 shows the different sequences of peptides sorted out for the present investigation.

\section{Tumor cell lines and cell culture}

The murine B16F10 cell line of melanoma cells was subcloned at the Experimental Oncology Unit, Federal University of São Paulo, UNIFESP and the cell line B16F10-Nex2 was obtained and deposited at Banco de Células Rio de Janeiro (BCRJ 0342). Cell lineages of human melanoma (A2058), human colon carcinoma (HCT), human breast cancer (MCF-7 and SKBR-3), mouse fibroblasts (3T3), murine melanocytes (melan-A) and human foreskin fibroblast (HF) were provided by Ludwig Institute for Cancer Research, São Paulo, Brazil and Dr. Luiz F. Lima Reis (Hospital Sirio-Libanez, São Paulo). Cells were cultured at $37{ }^{\circ} \mathrm{C}$, under humid atmosphere and $5 \% \mathrm{CO}_{2}$, in RPMI-1640 medium with $10 \mathrm{mM} \mathrm{N-2-hydroxyethylpiperazine-N2-}$ ethanesulphonic acid (HEPES), $24 \mathrm{mM}$ sodium bicarbonate, $40 \mathrm{mg} / \mathrm{L}$ gentamicin, $\mathrm{pH} 7.2$ and $10 \%$ fetal calf serum (FCS). U87-MG cell line
Table 1

Amino acid sequences of $17 \mathrm{CDR}$ peptides with their respective access codes from NCBI BLAST.

\begin{tabular}{lll}
\hline Peptide & Amino acid sequence & Access codes \\
\hline LA3-L1 & RASQGISSWLA & BAC80166.1 \\
B9-L1 & RASQSISSYLN & AEA48887.1 \\
C36-L1 & KSSQSVFYSSNNKNYLA & CAB44483.1 \\
MS1-L1 & TLSSGHSSYAIA & AAS21063.1 \\
MN20-L3 & QQYSGYPY & 2BRR_L \\
V330-H2 & VISYDGSYKYYADSVKG & BAI51287.1 \\
CM04A05-H2 & VISGSSGRTHYADSVKG & CAL06666.1 \\
D2-H2 & GIIPIFGAANYAQ & ABV70971.1 \\
CE48-H2 & INSGGGGTYYADSVKG & CAL04002.1 \\
Mg16-H2 & EIYYSGSTNYNPSLKS & ABI35660.1 \\
1-H2 & SLYYSGTTFYNPSLKS & CAD44679.1 \\
HA9-H2 & YIYYSGSTNYNPSLKS & AAO86898.1 \\
D07-H3 & DLRNHVFWSGYSTSFDY & ABE97346.1 \\
A7-H3 & DRGRGLISYYYYGMDV & AAW29179.1 \\
F1-H3 & ASYGSRGWYFDV & CAA80000.1 \\
F6-H3 & DQGGDDYGDYYYYYGMDV & ABP98185.1 \\
MS2-H3 & DTVMATPYYFDY & AAM88150.1 \\
\hline
\end{tabular}

(glioblastoma) was provided by Dr. Osvaldo K. Okamoto, University of São Paulo and was maintained in DMEM medium supplemented as for the RPMI-1640 medium.

\section{Cell viability assay}

Tumor cells $\left(10^{4}\right)$ were seeded in 96-well plates and incubated with all peptides at different concentrations ranging from 0 to $1 \mathrm{mM}$. Viable cells were quantified using the MTT (3-[4,5-dimethylthiazol-2-yl]-2,5-diphenyltetrazolium bromide) (Sigma-Aldrich, St. Louis, MO) assay. After $24 \mathrm{~h}$ of incubation with peptides, $10 \mu \mathrm{l}$ of MTT solution $(5 \mathrm{mg} / \mathrm{ml})$ in 16 phosphatebuffered saline (PBS) was directly added to the cells, followed by incubation for $3 \mathrm{~h}$ at $37^{\circ} \mathrm{C}$. Absorbance was measured at $570 \mathrm{~nm}$ with an automated spectrophotometric plate reader (SpectraMaxM2, Molecular Devices Software Pro 5.4, Sunnyvale, CA). Cell viability was expressed as percent values in comparison with untreated control cells. The experiments were performed in triplicate. Alternatively, viable cells were quantified using the Trypan Blue exclusion assay.

\section{Murine bone marrow cells and macrophage differentiation}

Fresh bone marrow cells were used to generate macrophages using L929-cell supernatant conditioned medium (LCCM) as a source of granulocyte/macrophage-colony stimulating factor (GMCSF). Cells were resuspended in $10 \mathrm{ml}$ bone marrow differentiation medium, which consists of RPMI-1640 (Gibco, Grand Island, NY) supplemented with $20 \%$ fetal bovine serum (Gibco, Grand Island, $\mathrm{NY}$ ), 30\% LCCM, $100 \mathrm{U} / \mathrm{ml}$ penicillin, $100 \mathrm{mg} / \mathrm{ml}$ streptomycin, and $2 \mathrm{mM} \mathrm{L-glutamine.} \mathrm{Cells} \mathrm{were} \mathrm{seeded} \mathrm{in} \mathrm{non-tissue} \mathrm{culture} \mathrm{treated}$ Optilux Petri dishes (BD Biosciences, Franklin Lakes, NJ) and incubated at $37^{\circ} \mathrm{C}$ in $5 \% \mathrm{CO}_{2}$ atmosphere. After 4 days, $10 \mathrm{ml}$ of fresh medium was added per plate and incubated for additional 3 days. To obtain macrophages, the supernatants were discarded and the adherent cells were washed with $15 \mathrm{ml}$ of sterile PBS. Macrophages were detached gently using a cell scraper and PBS. The cells were centrifuged at $200 \times \mathrm{g}$ for $5 \mathrm{~min}$ and resuspended in $10 \mathrm{ml}$ of RPMI 1640 (Gibco, Grand Island, NY). Cells were counted and cultured in tissue culture plates for $12 \mathrm{~h}$.

\section{Macrophage NO production}

Nitric oxide (NO) production was assessed by measuring the accumulation of nitrite in the culture medium using the Griess reaction. $5 \times 10^{5}$ Bone marrow macrophages were seeded in 24-well 


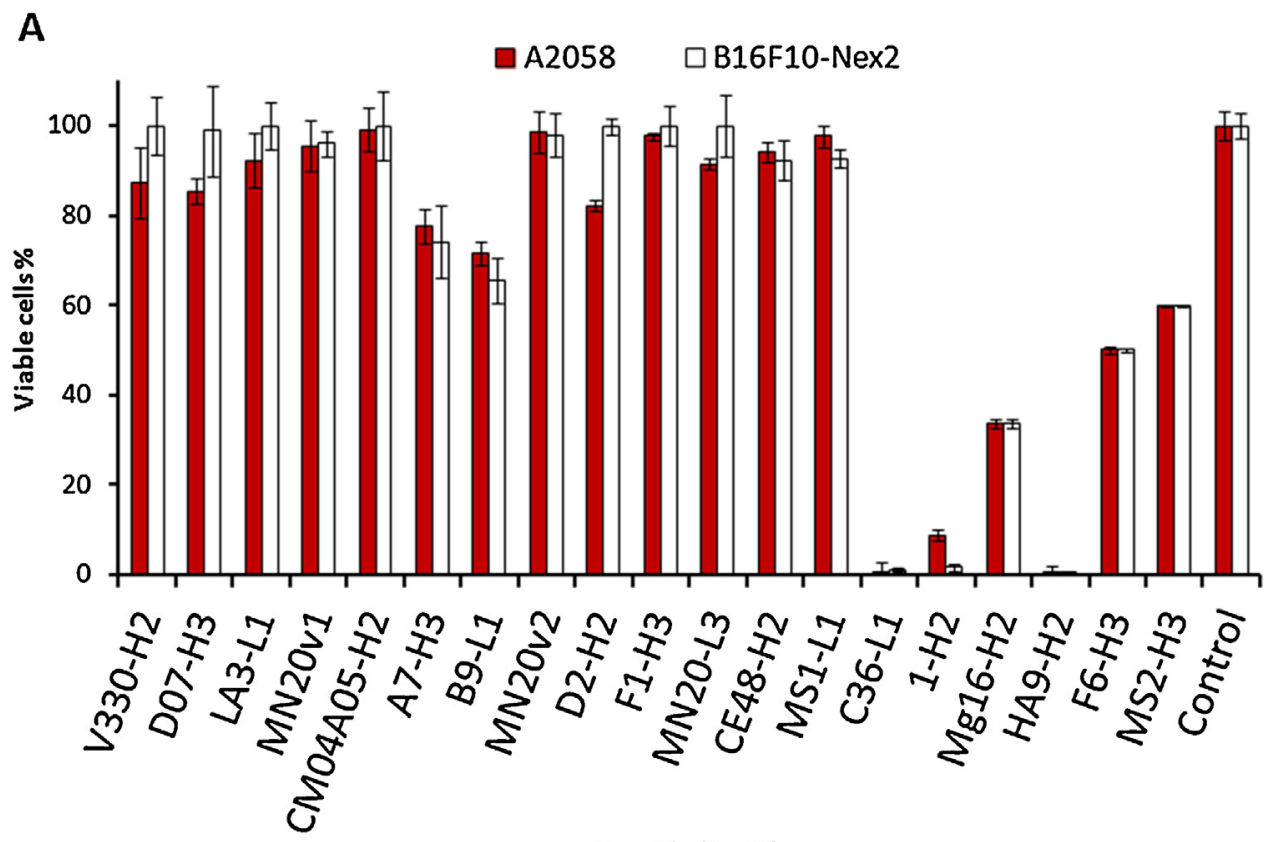

B

Peptide (1mM)

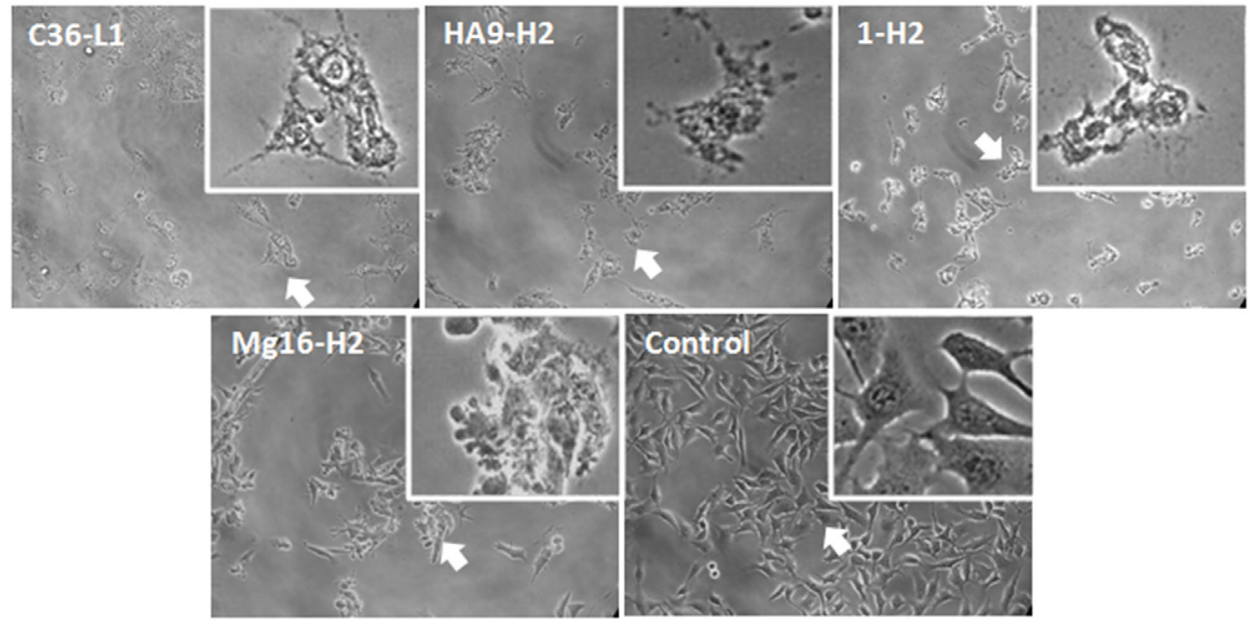

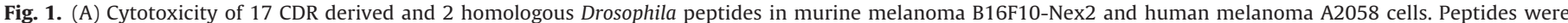

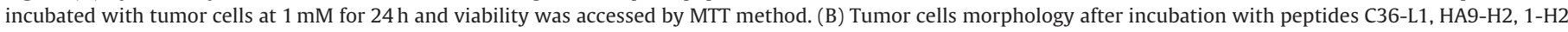
and $\mathrm{Mg} 16-\mathrm{H} 2$. All experiments were made in triplicate.

plates and incubated at $37^{\circ} \mathrm{C}, 5 \% \mathrm{CO}_{2}$ for $6 \mathrm{~h}$. Adherent macrophages were stimulated with LPS $(200 \mathrm{ng} / \mathrm{ml})$, IFN- $\gamma(100 \mathrm{U} / \mathrm{ml})$ or a combination of the two in the presence or not of each peptide for $72 \mathrm{~h}$. Supernatants were harvested and mixed with equal volumes of Griess reagent ( $1 \%$ sulfanilamide and $0.1 \%$ napthylethylenediamine dihydrochloride in $2.5 \%$ phosphoric acid) and incubated at room temperature for $10 \mathrm{~min}$. NO was quantified by absorption in a microplate reader at $550 \mathrm{~nm}$ (Spectramax m2e, Molecular Devices), and converted based on a nitrite standard curve [5]. Untreated cells and cells treated with IFN- $\gamma$ or LPS or both without adding the peptides were the controls used.

\section{Metastatic melanoma assay}

Male, 7-8-week-old C57Bl/6 mice were injected endovenously with $5 \times 10^{5}$ syngeneic B16F10-Nex2 viable cells in $0.1 \mathrm{ml} \mathrm{RPMI}$ per animal. For antitumor protection experiments, two groups of mice were challenged with tumor cells and treated on the next day with intraperitoneal (i.p.) doses of $300 \mu$ g peptide in $100 \mu \mathrm{l}$ of PBS during 5 consecutive days. After 12-15 days, lungs were collected and inspected for metastatic colonization and the black metastatic nodules counted. Animals challenged e.v. with tumor cells and treated with PBS alone without peptides were the controls used.

\section{Results}

CDR peptides studied in the present work were sorted out from monoclonal antibodies reported in the literature to specifically recognize antigenic epitopes on eukaryotic and prokaryotic cells, and viruses. Table 1 shows the different amino acid sequences of CDR peptides investigated in the present work. Aiming at an initial screen for bioactivity using macrophages and tumor cells as targets the various peptides were tested for cytotoxicity effects, NO production and protective activities using a syngeneic murine metastatic melanoma model. 

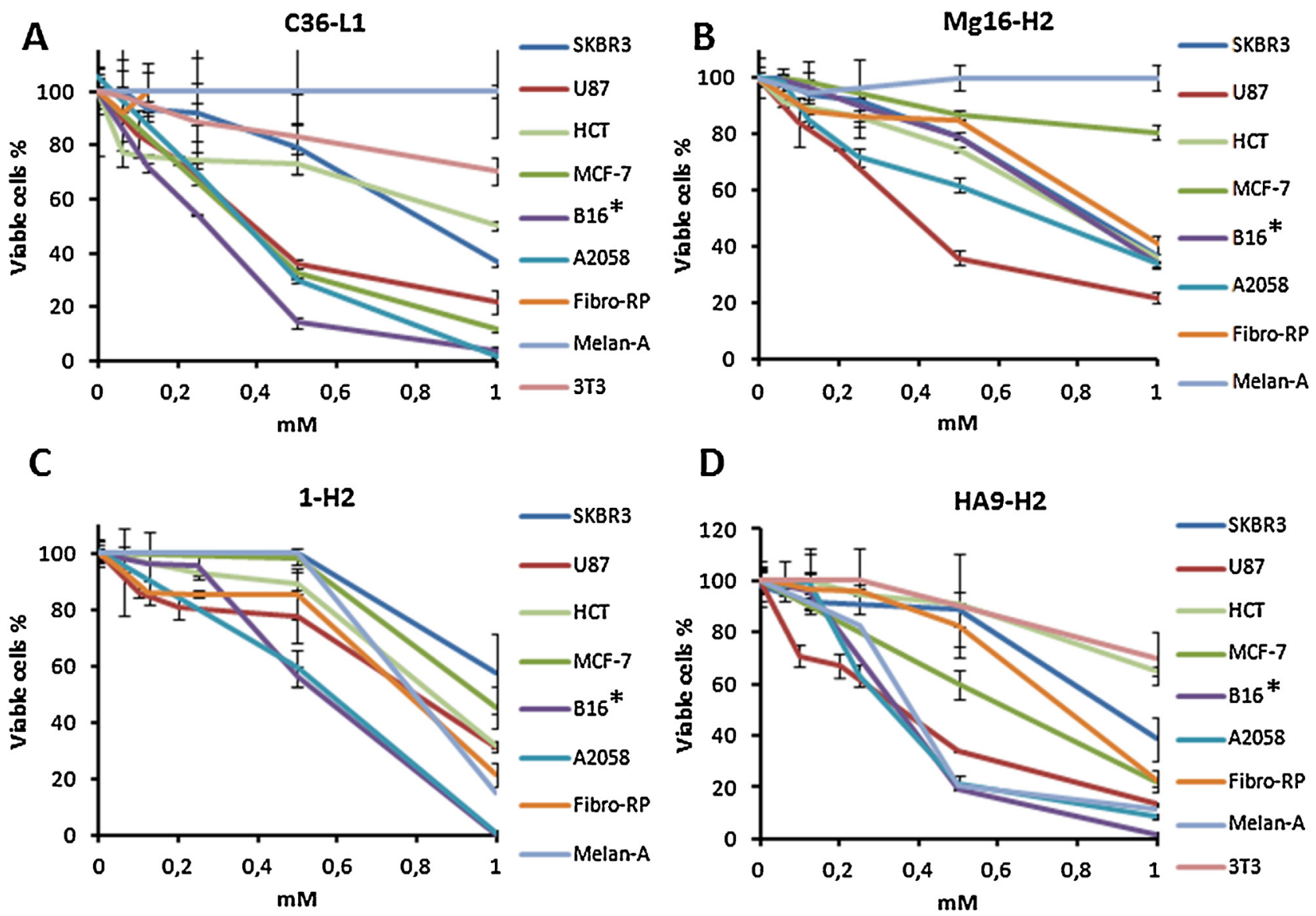

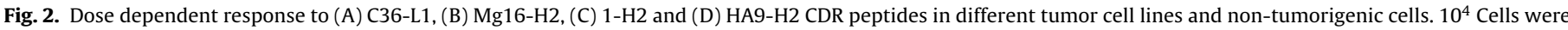
incubated with different concentrations of each peptide ranging from 0 to $1 \mathrm{mM}$. ${ }^{*} \mathrm{~B} 16=\mathrm{B} 16 \mathrm{~F} 10$-Nex2. Results are means of three independent experiments.

\section{In vitro cytotoxicity of $C D R$ peptides}

The cytotoxicity of all CDR peptides was evaluated on B16F10Nex2 murine melanoma and A2058 human melanoma cells at $1 \mathrm{mM}$ for $24 \mathrm{~h}$. We observed that peptides C36-L1, HA9-H2, 1-H2 and $\mathrm{Mg} 16-\mathrm{H} 2$ were the most cytotoxic and significantly reduced tumor cells viability as shown in Fig. 1A. In Fig. 1B, morphological alterations in B16F10-Nex2 cells incubated with peptides C36-L1, HA9-H2, 1-H2 and Mg16-H2 are shown. White arrows and inserts reveal cytoplasm shrinkage in melanoma cells treated with peptides C36-L1, HA9-H2 and 1-H2, and partial fragmentation into discrete bodies, which are frequently referred to as 'apoptotic bodies' [16], with peptide Mg16-H2. Peptides F6-H3, MS2-H3, B9-L1 and A7-H3 also showed a significant activity in vitro, partially affecting tumor cells viability. We also tested two Drosophila peptides analogous to MN20-L3 CDR, the MN20v1 (QQYSGYPY-NH $\mathrm{N}_{2}$ ) and MN20v2 (QQYSGYPY- $\mathrm{NH}_{2}$ ). Both peptides, however, were not active against tumor cells in vitro.

The growth inhibition of the most active peptides in vitro, C36L1, HA9-H2, 1-H2 and Mg16-H2, was evaluated on different tumor and non-tumorigenic cell lineages as shown in Fig. 2 and the $\mathrm{IC}_{50}$ values determined (Table 2). Peptide C36-L1 was the most active peptide found in this screening showing low $\mathrm{IC}_{50}$ values (0.23-0.5 mM) against murine melanoma B16F10-Nex2, human melanoma A2058, human glioblastoma U87 and human breast cancer MCF-7. This peptide was not inhibitory against non-tumorigenic cells including melan $\mathrm{A}$, as indicated in Fig. 2A and Table 2. In contrast, peptide HA9-H2 significantly inhibited non-tumorigenic cells, except for NIH-3T3 fibroblasts. Peptides Mg16-H2 and 1-H2 were less active against all tumor cells as shown in Fig. 2B and C and Table 2.

In vivo anti-metastatic assay

The in vivo antitumor activity of all peptides was investigated in a syngeneic murine metastatic model, with B16F10-Nex2 tumor cells and $\mathrm{C} 57 \mathrm{BL} / 6 \mathrm{H}-2^{\mathrm{b}}$ mice. We observed that peptides $\mathrm{C} 36-\mathrm{L} 1$, HA9-H2, 1-H2, Mg16-H2, D07-H3, MN20v1 and MS2-H3 induced significant protection against metastatic melanoma reducing the number of lung metastatic nodules (Fig. 3). No protection was observed with the other CDR peptides (LA3-L1, B9-L1, MS1-L1, MN20-L3, V330-H2, CM04A05-H2, D2-H2, CE48-H2, A7-H3, F1H3, F6-H3) and the Drosophila MN20v2 analog. Responses were

Table 2

$\mathrm{IC}_{50}$ values obtained for $\mathrm{C} 36-\mathrm{L} 1,1-\mathrm{H} 2$, HA9-H2 and $\mathrm{Mg} 16-\mathrm{H} 2 \mathrm{CDR}$ peptide activities against different tumor cell and non-tumorigenic cell lineages.

\begin{tabular}{llccc}
\hline \multirow{2}{*}{ Cell lineage } & \multicolumn{4}{l}{ Peptide-IC $50(\mathrm{mM})$} \\
\cline { 2 - 5 } & C36-L1 & 1-H2 & HA9-H2 & Mg16-H2 \\
\hline B16F10-Nex2 & 0.235 & 0.56 & 0.45 & 0.82 \\
A2058 & 0.35 & 0.53 & 0.25 & 0.70 \\
U87 & 0.50 & 0.76 & 0.36 & 0.95 \\
SKBr-3 & 0.84 & $>1$ & 0.9 & $>1$ \\
HCT & 0.95 & 0.89 & 0.82 & $>1$ \\
MCF-7 & 0.3 & 0.98 & 0.63 & $>1$ \\
Melan-A & $>1$ & 0.85 & 0.32 & $>1$ \\
Fibro-RP & $>1$ & 0.82 & 0.78 & 0.94 \\
NIH-3T3 & $>1$ & 0.92 & $>1$ & $>1$ \\
\hline
\end{tabular}



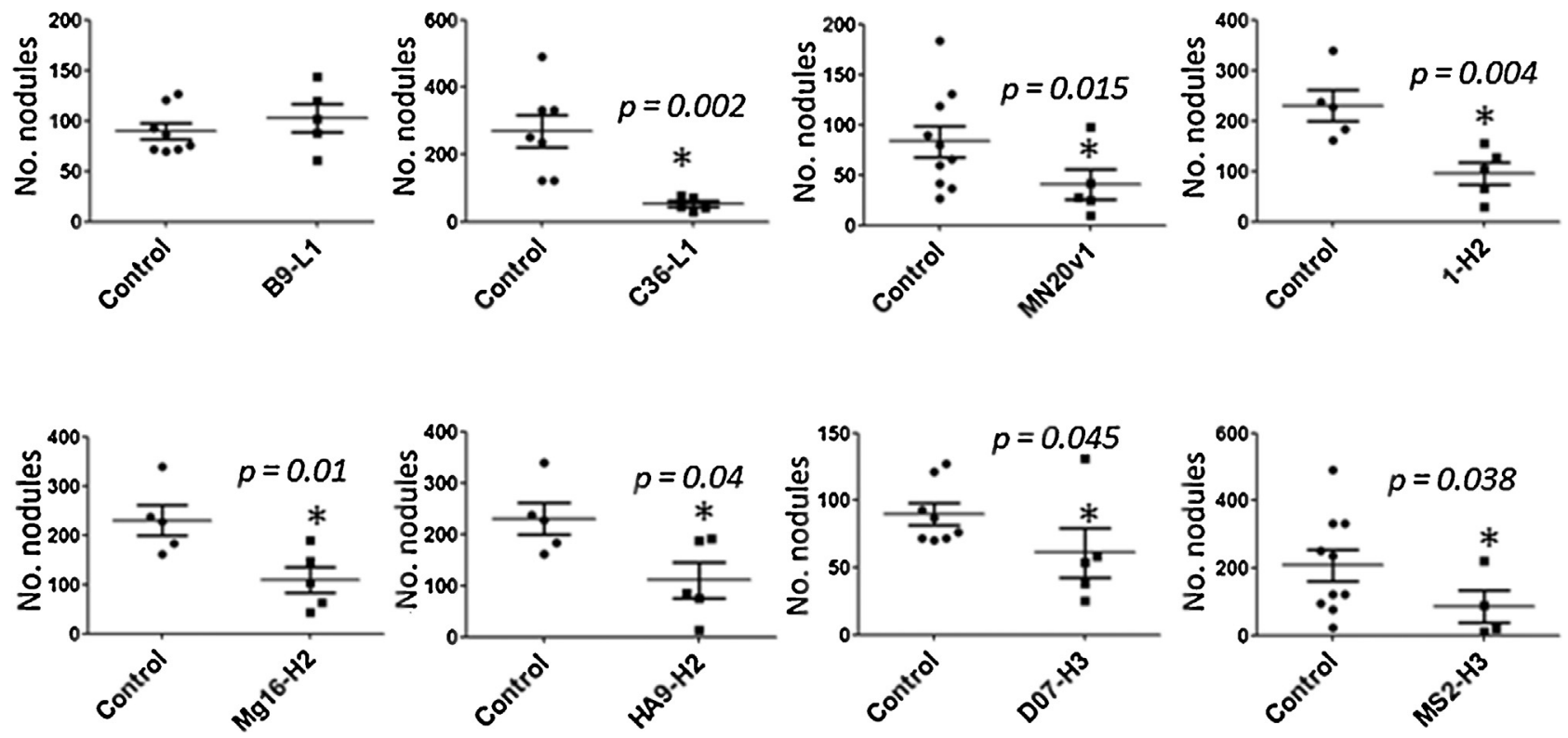

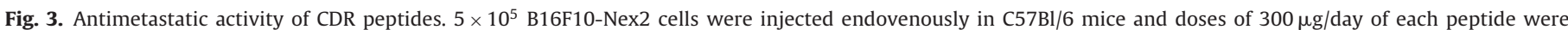

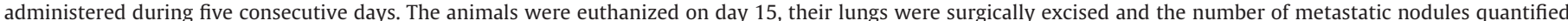
under a Stereo Microscope (Nikon). At least three experiments were made for each peptide.

similar to that observed for B9-L1 peptide (Fig. 3). In addition, no toxic effects, loss of weight, or alterations in animal behavior were observed during the treatment with all peptides.

\section{In vitro macrophage activation assay}

Peptides C36-L1 and 1-H2, which were both active against B16F10-Nex2 cells in vitro and in vivo, also induced significant production of NO in IFN- $\gamma$-induced macrophages (Fig. 4). D07$\mathrm{H} 3$ elicited high NO production in macrophages and also induced significant antitumor protection in vivo. Peptide MN20v1, which elicited significant antitumor protection in vivo and NO production in vitro, was not directly cytotoxic against B16F10-Nex2 cells (Fig. 1), suggesting participation of the immune system. MS2-H3, which was protective in vivo, induced significant NO production in IFN- $\gamma$ and LPS activated macrophages, and was moderately

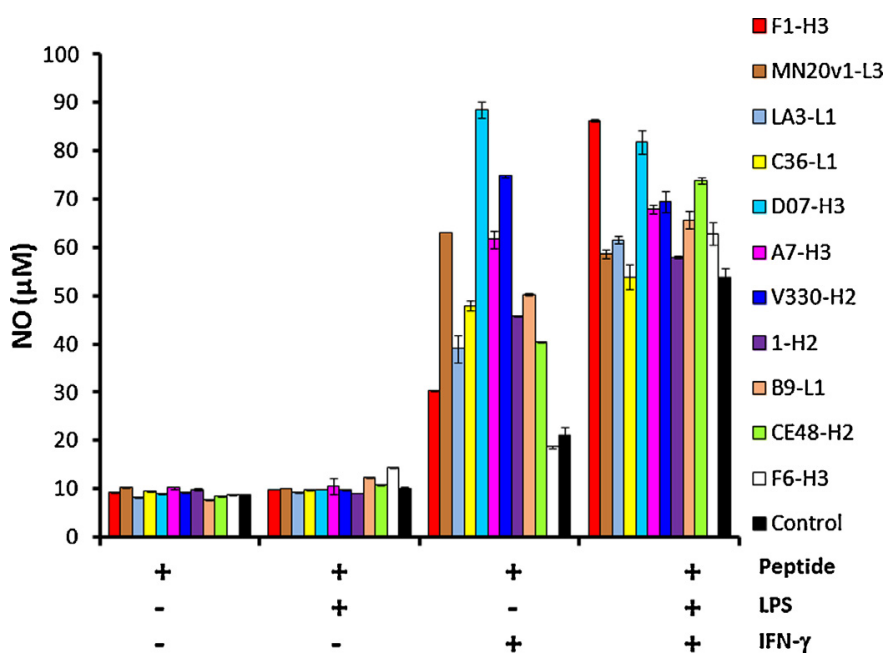

Fig. 4. Macrophage NO production induced by CDR peptides. Peptides at $100 \mu \mathrm{M}$, were incubated for $72 \mathrm{~h}$ with macrophages in the presence or absence of LPS $(200 \eta \mathrm{g} / \mathrm{ml})$ and IFN $-\gamma(100 \mathrm{U} / \mathrm{ml})$. NO production was assayed using $100 \mu \mathrm{l}$ of Griess reagent. Controls (black bars) were run without the peptides, for each group. Two experiments were made with four determinations for each peptide. active against B16F10-Nex2 cells in vitro. F1-H3 also induced NO production in IFN- $\gamma$ activated macrophages but was poorly protective in vivo (Fig. 3). NO production by IFN- $\gamma$ and LPS treated macrophages treated with the other CDRs (LA3-L1, B9-L1, MS1L1, MN20-L3, V330-H2, CM04A05-H2, D2-H2, CE48-H2, Mg16-H2, HA9-H2, A7-H3, F6-H3), was similar or lower than that with MS1-L1 peptide.

\section{Discussion}

Following the pivotal work by Polonelli et al. [24] further research on the antitumor activity of CDRs $[2,9,19]$ showed a frequency of 1-2 CDRs per monoclonal antibody exerting anti-cancer properties in vitro, in vivo or both. Of 6 CDRs, the most frequently active were $\mathrm{L} 1, \mathrm{H} 2$ and $\mathrm{H} 3$. In the present work we confirmed this preference testing 17 CDRs and 2 analogous Drosophila peptides.

Screening of active CDRs used the corresponding synthetic peptides amidated at the $C$ terminal and included a short number of in vitro and in vivo tests. Most tests used B16F10-Nex2 murine melanoma cells, and a few were run with a panel of human cancer lineages and also with non-tumorigenic cells.

Since several CDR peptides induced apoptosis in tumor cells [24], the morphological characteristics of cells incubated with lethal concentrations of peptides could indicate programmed cell death (PCD), including rounding-up of cells, cytoplasm shrinkage, chromatin condensation, nuclear fragmentation and plasma membrane blebbing [16]. PCD may refer to apoptosis but also to autophagy and even programmed necrosis when mediated by an intracellular program deciding the fate of cells of malignant neoplasms [21].

The therapeutic activity of anticancer agents is limited by their toxicity exerted in proliferating cells, including normal cells [3]. Novel cytotoxic agents preferentially targeting cancer cells are thus a constant goal. In the present study, peptide C36-L1 emerged as a promising candidate for targeted cancer therapy.

The antitumor activity in vivo observed after systemic treatment with peptides could be related to a direct activity on the tumor, evidenced by the cytotoxic potential of peptides C36-L1, HA9-H2 and $1-\mathrm{H} 2$, but also as an effective participation of the immunological system since it has been reported that certain peptides 
are not protective in immune deficient animals [19]. In fact, the intraperitoneal injections in consecutive days used in our protocols with unprotected peptides, probably would not preclude proteolytic degradation and renal clearance, unless peptides are efficiently taken up by dendritic cells (DCs). Tumor antigen-primed DCs treated with CDR peptides conferred anti-tumor protection similar to the free peptide [19]. Therefore in those cases in which peptides were protective in vivo but poorly cytotoxic in vitro most probably an immune response was likely involved. Peptides D07$\mathrm{H} 3, \mathrm{MN20v} 1$ and MS2-H3, that were clearly protective in vivo, had poor or no significant activity against murine melanoma B16F10Nex2 cells in vitro, suggesting effects as adjuvants in protective immune responses.

Effector cells of innate immunity include granulocytes, natural killer cells and macrophages, all of them playing an important role in the antitumor immunity. In addition to the already described effects of CDR peptides, an immunomodulatory activity has been attributed to the CDR H3 from an anti-blood group A murine mAb. The peptide acted on macrophages, stimulating proinflammatory cytokine production, activating the PI3K-Akt pathway and promoting TLR-4 expression [11]. We observed that some CDR peptides that showed antitumor protection in vivo also induced significant NO production in IFN- $\gamma$-induced macrophages, providing another evidence that these peptides may act in the activation of an immune protective response. Recently, we showed (Figueiredo CR, unpublished results) that C36-L1-treated DCs were protective in the B16F10-Nex2 metastatic model, thus furthering the notion that CDR peptides may act as potent adjuvants for anti-tumor therapy.

Although a protective immune response against growing tumors may occur spontaneously, it usually fails to cause tumor regression. The use of immune adjuvants might be effective against early-stage developing tumors. It is questionable whether ex vivo-prepared DC vaccines are superior to in situ-administered adjuvant-guided vaccines [25]. Peptides have been described to protect against subcutaneous B16F10-Nex2 melanoma even when tumors reached $100-200 \mathrm{~mm}^{3}[19,20]$.

In conclusion, the evidence that Igs are a source of anti-tumor internal peptides mainly represented by the hypervariable CDRs is supported in the present work. CDR peptides from different families of immunoglobulins display a number of biological activities, such as direct activity on tumor cells and acting as immune adjuvants stimulating antitumor responses in vivo. Peptides can be synthesized in high amounts and purity and be kept lyophilized without loss of activity. They are inexpensive, naturally biodegradable and well tolerated. Some of the peptide sequences described, with antitumor activities in vitro and in vivo in a mouse syngeneic system, can be further studied aiming at a molecular therapy of malignant melanoma and other tumors.

\section{Acknowledgments}

We thank the Ludwig Institute for Cancer Research, São Paulo, and Drs. LF Lima Reis and OK Okamoto, for the cell lines used in the present study. This work was supported by Fundação de Amparo a Pesquisa do Estado de São Paulo (FAPESP), grant no. 2010/51423-0 and by the Brazilian National Research Council (CNPq).

\section{References}

[1] Al-Lazikani B, Lesk AM, Chothia C. Standard conformations for the canonical structures of immunoglobulins. J Mol Biol 1997;273:927-48.
[2] Arruda DC, Santos LC, Melo FM, Pereira FV, Figueiredo CR, Matsuo AL, et al. Beta-actin-binding complementarity-determining region 2 of variable heavy chain from monoclonal antibody C7 induces apoptosis in several human tumor cells and is protective against metastatic melanoma. J Biol Chem 2012;287:14912-22

[3] Chari RV. Targeted cancer therapy: conferring specificity to cytotoxic drugs Accounts Chem Res 2008;41:98-107.

[4] Chothia C, Lesk AM. Canonical structures for the hypervariable regions of immunoglobulins. J Mol Biol 1987;196:901-17.

[5] Clarke JH, Cha JY, Walsh MD, Gamboni-Robertson F, Banerjee A, Reznikov LL et al. Melanoma inhibits macrophage activation by suppressing toll-like receptor 4 signaling. J Am Coll Surg 2005;201:418-25.

[6] De Smet K, Contreras R. Human antimicrobial peptides: defensins, cathelicidins and histatins. Biotechnol Lett 2005:27:1337-47.

[7] Deepak KDJ, Shrivastava V, Kakde R, Patil AT. Cancer therapeutics - opportunities, challenges and advances in drug delivery. J Appl Pharm Sci 2011, 01:10.

[8] Delaroche D, Cantrelle FX, Subra F, Van Heijenoort C, Guittet E, Jiao CY, et al. Cellpenetrating peptides with intracellular actin-remodeling activity in malignant fibroblasts. J Biol Chem 2010;285:7712-21.

[9] Dobroff AS, Rodrigues EG, Juliano MA, Friaca DM, Nakayasu ES, Almeid IC, et al. Differential antitumor effects of IgG and IgM Monoclonal antibodies and their synthetic complementarity-determining regions directed to new targets of B16F10-Nex2 melanoma cells. Transl Oncol 2010;3: 204-17.

[10] Eldar-Finkelman H, Eisenstein M. Peptide inhibitors targeting protein kinases. Curr Pharm Des 2009;15:2463-70.

[11] Gabrielli EPE, Cenci E, Ortelli F, Magliani W, Ciociola T, Bistoni F, et al. Antibody complementarity-determining regions (CDRs): a bridge between adaptive and innate immunity. PLoS One 2009;4

[12] Gabrielli E, Pericolini E, Cenci E, Ortelli F, Magliani W, Ciociola T, et al. Antibody constant region peptides can display immunomodulatory activity through activation of the Dectin-1 signalling pathway. PLoS One 2012; 7:e43972.

[13] Gaspar D, Veiga AS, Castanho MA. From antimicrobial to anticancer peptides. A review. Front Microbiol 2013;4:294.

[14] Heap CJ, Wang Y, Pinheiro TJ, Reading SA, Jennings KR, Dimmock NJ. Analysis of a 17-amino acid residue, virus-neutralizing microantibody. J Gen Virol 2005; $86: 1791-800$

[15] Kabat EA. Sequences of proteins of immunological interest. U.S. Department of Health and Human Services, Public Health Service, National Institutes of Health; 1991

[16] Kroemer G, Galluzzi L, Vandenabeele P, Abrams J, Alnemri ES, Baehrecke EH, et al. Classification of cell death: recommendations of the Nomenclature Committee on cell death 2009. Cell Death Differ 2009;16:3-11.

[17] Litman GW, Cannon JP, Dishaw LJ. Reconstructing immune phylogeny: new perspectives. Nat Rev Immunol 2005:5:866-79.

[18] Magliani W, Conti S, Cunha RL, Travassos LR, Polonelli L. Antibodies as crypts of antiinfective and antitumor peptides. Curr Med Chem 2009;16: 2305-23.

[19] Massaoka MHMA, Scutti JAB, Arruda DC, Rabaça A, Figueiredo CR, Farias CF, et al. Melanoma: perspectives of a vaccine based on peptides. In: Molecular vaccine. Wien: Springer-Verlag; 2013.

[20] Massaoka MH, Matsuo AL, Figueiredo CR, Girola N, Faria CF, Azevedo RA et al. A novel cell-penetrating peptide derived from WT1 enhances p53 activity, induces cell senescence and displays antimelanoma activity in xeno- and syngeneic systems. FEBS Open Bio 2014;4:153-61.

[21] Ouyang L, Shi Z, Zhao S, Wang FT, Zhou TT, Liu B, et al. Programmed cell death pathways in cancer: a review of apoptosis, autophagy and programmed necrosis. Cell Prolif 2012;45:487-98.

[22] Polonelli L, Ciociola T, Magliani W, Zanello PP, D’Adda T, Galati S, et al. Peptides of the constant region of antibodies display fungicidal activity. PLoS One 2012; 7:e34105

[23] Polonelli L, Magliani W, Conti S, Bracci L, Lozzi L, Neri P, et al. Therapeutic activity of an engineered synthetic killer antiidiotypic antibody fragment against experimental mucosal and systemic candidiasis. Infect Immun 2003;71:6205-12.

[24] Polonelli L, Ponton J, Elguezabal N, Moragues MD, Casoli C, Pilotti E, et al. Antibody complementarity-determining regions (CDRs) can display differential antimicrobial, antiviral and antitumor activities. PLoS One 2008;3: e2371.

[25] Schijns VTE, Michalek J, Stathopoulos A, Dobrovolskienè NT, Strioga MM Immune adjuvants as critical guides directing immunity triggered by therapeutic cancer vaccines. Cytotherapy 2014;16:13.

[26] Thundimadathil J. Cancer treatment using peptides: current therapies and future prospects. J Amino Acids 2012;2012:967347.

[27] Tonelli R, Purgato S, Camerin C, Fronza R, Bologna F, Alboresi S, et al. Anti-gene peptide nucleic acid specifically inhibits MYCN expression in human neuroblastoma cells leading to cell growth inhibition and apoptosis. Mol Cancer Ther 2005;4:779-86. 